\title{
Japanese debate more or better links
}

\section{Tokyo}

JAPANESE researchers who would like to expand a computer network to many more universities are lining up against a powerful government agency that wants instead to improve service to a smaller number of existing sites.

The scientists would like to see more regional networks that would connect smaller universities and research institutes in the more remote regions of the country with high-speed access to international scientific networks. But the powerful National Centre for Science Information Systems (NACSIS), which oversees the domestic development of computer networks in Japan's universities, wants the government to concentrate instead on a super-high-capacity computer link between the Kanto region around Tokyo and the Kansai region around Kyoto and Osaka, where most of Japan's research activity is concentrated.

Last week, Tsuneyoshi Kamae of the physics department of Tokyo University invited a handful of leading information scientists from Japan's universities and industry to an informal meeting to discuss how to develop such a regional computer networks. In 1989, Kamae almost single-handedly established the Todai International Science Network (TISN), a highcapacity computer link with the West that was Japan's first such link for general scientific use (Nature 340, 670; 1989).

TISN has expanded rapidly despite having no official backing of any government ministry or agency. Users simply pay $\$ 10,000$ towards the international link to Hawaii and install their own domestic link to TISN in Japan. Beginning at Tokyo University, TISN now connects nearly 20 of Japan's national universities and research institutes in a network that provides a 64-kilobit-a-second link to the University of Hawaii. From Hawaii, researchers gain access to scientific networks around the world.

Among the most recent groups to join TISN are Japan's genome researchers. Researchers belonging to the human genome project of the Ministry of Education, Science and Culture (MESC) have linked TISN to their genome network, which connects computers in Osaka University, Kyoto University and the $\mathrm{Na}$ tional Institute of Basic Biology in Okazaki to the new human genome research centre in the Institute of Medical Science in Tokyo University. And they plan to extend the genome network to Kyushu University in Japan's southern island of Kyushu.

Rice genome researchers working under the Ministry of Agriculture, Forestry and Fisheries also plan to tap into TISN. And human genome researchers under the
MESC in Tokyo in 1986 to help build computer links among universities. With an annual budget of about $¥ 3,000$ million (US\$22 million), NACSIS has placed hundreds of computers and packet switching nodes in universities all over Japan and linked them with high-speed digital circuits.

\section{Japan's international computer network keeps growing}

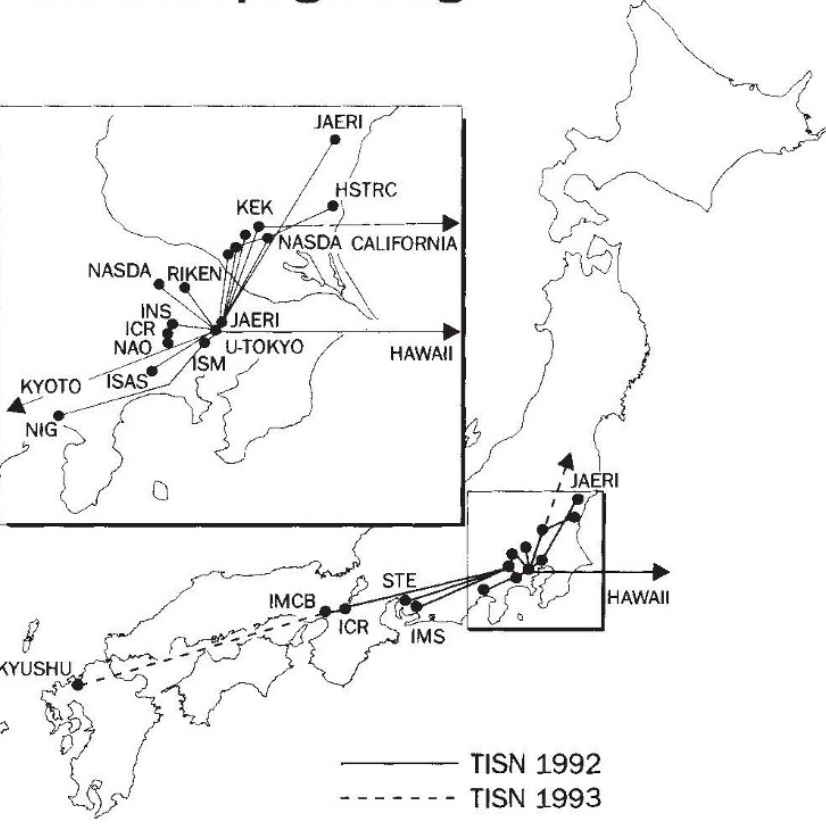

JAERI Japan Atomic Energy Research institute, KEK National Laboratory for High Energy Physics, NASDA National Space Develpment Agency, NAO National Astronomical Observatory, ISAS The Institute of Space and Astronautical Institute of Genetics, IMS Institute for Molecular Science, Chemical Research, Kyoto University, IMCB Institute for Molecular and Cellular iology, Osaka University, RIKEN Institute of Physical and Chemical Research, NS Institute for Nuclear Study, ISM The Institute for Statistical Mathematics, Science and Technology Agency, who are planning to link the Japan Information Centre of Science and Technology (JICST) to the Genome Data Bank (GDB) in Johns Hopkins University in the United States, also intend to link JICST to TISN so that all of Japan's genome researchers can access GDB.

Paralleling the development of TISN is another high-capacity computer network called the Widely Integrated Distributed Environment (WIDE). Established by Jun Murai of Keio University with donations from Japanese industry, WIDE is intended primarily for those who are developing computer networks. But university researchers also use it to gain international access to overseas computer networks.

Lumbering along behind these pioneering efforts is NACSIS, established by
But NACSIS is handicapped by its decision to use a littleknown protocol called $\mathrm{N}-1 . \mathrm{N}-1$ was developed domestically in the 1970 s with a grant from MESC. But computer networks that use the $\mathrm{N}-1$ protocol are unable to communicate with computer networks outside Japan that use other protocols, in particular the widely used TCP/ IP protocol.

In January 1989, NACSIS opened with much fanfare a high-capacity computer link with the National Science Foundation (NSF) in Washington. At the time, Japanese officials said it would open up the country's scientific information resources to the West. But the NSF link is essentially a dead end: because of protocol and other incompatibilities, US computer users cannot access it.

Shoichiro Asano of NACSIS admits that the NSF link has not been put to much use. He says that his centre has just established another high-capacity link to the United States that uses the TCP/IP protocol and that the NSF link will be "removed". NACSIS has also been gradually converting its domestic scientific network to the TCP/ IP protocol over the past few years. And NACSIS will this month open a backbone TCP/IP network of nine new nodes, called SINET, that links Sapporo in the northern island of Hokkaido to Hakata in Kyushu.

While this switch to TCP/IP is welcomed by Japan's scientists, there is disagreement about what should happen next. Kamae and other pioneers of networks in Japan, like Shoichi Noguchi, director of the Research Centre for Applied Information Sciences in Tohoku University, would like the government to invest in regional computer networks so that small local universities and research institutes can tap into the new high-speed networks.

"I can communicate much more quickly and efficiently by computer with Oxford University in the United Kingdom on the other side of the globe than I can with Gumma University just outside Tokyo", says Kamae. Many small regional univer- 
sities like Gumma still only have 9.6-kilobit links to the NACSIS scientific inter-university network. In addition, the regional universities lack local area networks on campus, and the national universities are acquiring them only slowly, at a rate of one or two a year.

Asano of NACSIS admits that the issue of regional networks is "very political". But he argues that it is premature to establish such networks because there is a lack of "human resources" to manage them. A central management system is needed, he says, a job that the centre is starting to take on. In the meantime, NACSIS is concentrating on a plan to establish a six-megabit, super-high-capacity link between Tokyo and Kyoto.

But Kamae and his colleagues see no need for it. "We can easily supply that route with existing networks", Kamae says. "What is needed now is a bottoms-up approach".

It is not clear how such disagreements will be resolved. But even if NACSIS goes ahead with its plans, as seems likely, Kamae and his colleagues have already shown a remarkable capacity to establish links outside the NACSIS system.

David Swinbanks

\section{Who pulled the plug?}

UNIVERSITY scientists outside Japan who try in December to communicate via computer with their Japanese counterparts should not be surprised if the line suddenly goes dead for a few days. The silence is a result of government auditors trying to save the taxpayer a few yen.

Every year the National Centre for Science Information Systems (NACSIS) pulls the plug on the nation's university computer network to allow telecommunications carriers to bid on a contract to operate the system. Japan has several domestic telecommunication companies whose rates vary. And government financial auditors insist that the carriers must bid every year to provide the cheapest telecommunication links for NACSIS's nationwide computer network. To allow fair bidding, no carrier can provide telecommunication links for the computer network during the bidding process, which takes several days.

Last December, Japan was cut off from the outside scientific world for as much as a week. Shoichiro Asano of NACSIS says he is trying to shorten the bidding process. The centre also plans to install a back-up system using ordinary telephone lines so that the network remains open even during the bidding. D.S.

\section{NSF pays price for success}

\section{Washington}

WIDESPREAD acclaim, heady funding increases and thousands of satisfied scientists would be a dream come true for most science projects. But for the five-year-old computer network initiative of the $\mathrm{Na}$ tional Science Foundation (NSF), success has also meant a lot of headaches.

The initiative, called NSFNet, has grown steadily since it was created in 1987 as a nationwide 'backbone' research network. Earlier this year, the Administration requested more than $\$ 45$ million in 1993 for the agency's networking efforts, an increase of 38 per cent. In December, President George Bush signed legislation creating a National Research and Education Network (NREN) based on the NSFNet backbone. With annual funding expected to reach $\$ 1,000$ million by 1996 , NREN intends to connect not only research institutions but also schools and industry to a electronic web operating at 1,000 million bits per second.

It did not escape the notice of big business that all that money and responsibility was going to a little science agency. Longdistance telephone companies such as US Sprint also want to get into nationwide computer networking, and they complained bitterly that NSF had essentially handed over a potentially lucrative market to a handful of companies. The main contract had gone to Merit, Inc. (a non-profit consortium of Michigan universities) and Merit's subcontractors MCI and IBM, which handle the fibre optic lines and the routing hardware respectively. The three contractors then formed a fourth entity, Advanced Network and Services, Inc. (ANS), to handle network operations.

In its original plan, NSF had planned to 'recompete' its five-year contract with Merit in November. Normally, that would mean a simple request for applications and a selection of the winner. But pressure on the agency from the telecommunications industry has forced it to abandon its usual methods. Last year, it decided to extend the current contract by 18 months so that it could come up with a plan that would be fair to all concerned.

In the next week or two, NSF plans to issue a proposed solicitation for public comment. After weighing the comments, it will issue a final solicitation, and make awards in April 1993. Rather than retaining a single main contractor, NSF will make at least two awards for the lines and a third award for the routing equipment.

The process is a far cry from the type of small grants that NSF usually awards. "It keeps me up at night", admits Steven Wolff, director of the agency's network division.

Although congressional staff credit Wolff with making the best of a situation that simply got out of control, others say that NSF will not for long be able to balance the research community with the telecommunications industry. Some predict that NSF will be forced to privatize the network within a few years. "This thing has been growing even faster than NSF expected - they just ran up against telecommunications policy," says Frederick Weingarten, executive director of the Computing Research Association, a coalition of research universities.

Weingarten traces the problem to the mandate in the NREN legislation to serve society, not just the research community. "Once the [Administration] got the word education' into the title, it became tied up with a much bigger vision of building a national [network] infrastructure," he says.

When the telecommunications companies saw the scope of the legislation and the role that NSF would play in the network's development, they asked why a science agency - not to mention the US government - was in essence building the next telephone system. At a hearing in March before the House Science, Space and Technology subcommittee on science, industry officials complained that the NSF contract to Merit, IBM, MCI and ANS would allow those companies to essentially monopolize what promised to be a nationwide telecommunications network far beyond the research community.

"The entire group, which is now publicly self-characterized as a 'partnership', has total control over the $\$ 50$ million NSFNet backbone contract ... and [is] well positioned to win any NREN contracts in the future," complained William Schrader, president of Performance Systems International, a network services company.

Wolff acknowledges that the plunge into telecommunications policy has been a shock to NSF, but he is optimistic that the recompetition will allow the agency to continue to serve researchers and give companies a chance to compete. The government entered the field, he says, because scientists were not perceived to be a sufficiently lucrative market.

Once the recompetition is completed, NSF's next problem will be to know when to bow out. The network will someday connect commercial databases, schools and companies, and, if the lack of agreement among industry forces the agency to run the network for another five years or so, NSF may find it difficult to keep the focus on the research community.

On the other hand, giving it up too soon may leave researchers adrift. "NSF's not the right agency to run a nationwide network, says Weingarten. "But when it's finally taken out of their hands, I hope [the new owners] don't lose the ability to serve the research community as well."

Christopher Anderson 